\title{
Test yourself question: fullness in the left axilla
}

\section{R Rajakulasingam ${ }^{1}$ (1) - A Saifuddin ${ }^{1}$}

Published online: 19 May 2020

(C) ISS 2020

\section{Question}

A 32-year-old male presented with fullness in the left axilla. Ultrasound suggested a lipoma, but MRI was recommended for confirmation (Figs. 1 and 2).

\section{Compliance with ethical standards}

The diagnosis can be found at doi: https://doi.org/10.1007/s00256-02003467-z

\footnotetext{
R Rajakulasingam

Ramanan.rajakulasingam1@nhs.net
}

A Saifuddin

Asif.saiffudin@nhs.net

1 Department of Radiology, Royal National Orthopaedic Hospital, Brockley Hill, Stanmore, Middlesex HA7 4LP, UK
Conflict of interest The authors declare that they have no conflict of interest.

Publisher's note Springer Nature remains neutral with regard to jurisdictional claims in published maps and institutional affiliations. 
Fig. 1 a and b Coronal T1W TSE MR images of the left axilla

Fig. 2 a-d Selected axial PDW FSE MR images through the left axilla from cranial to caudal
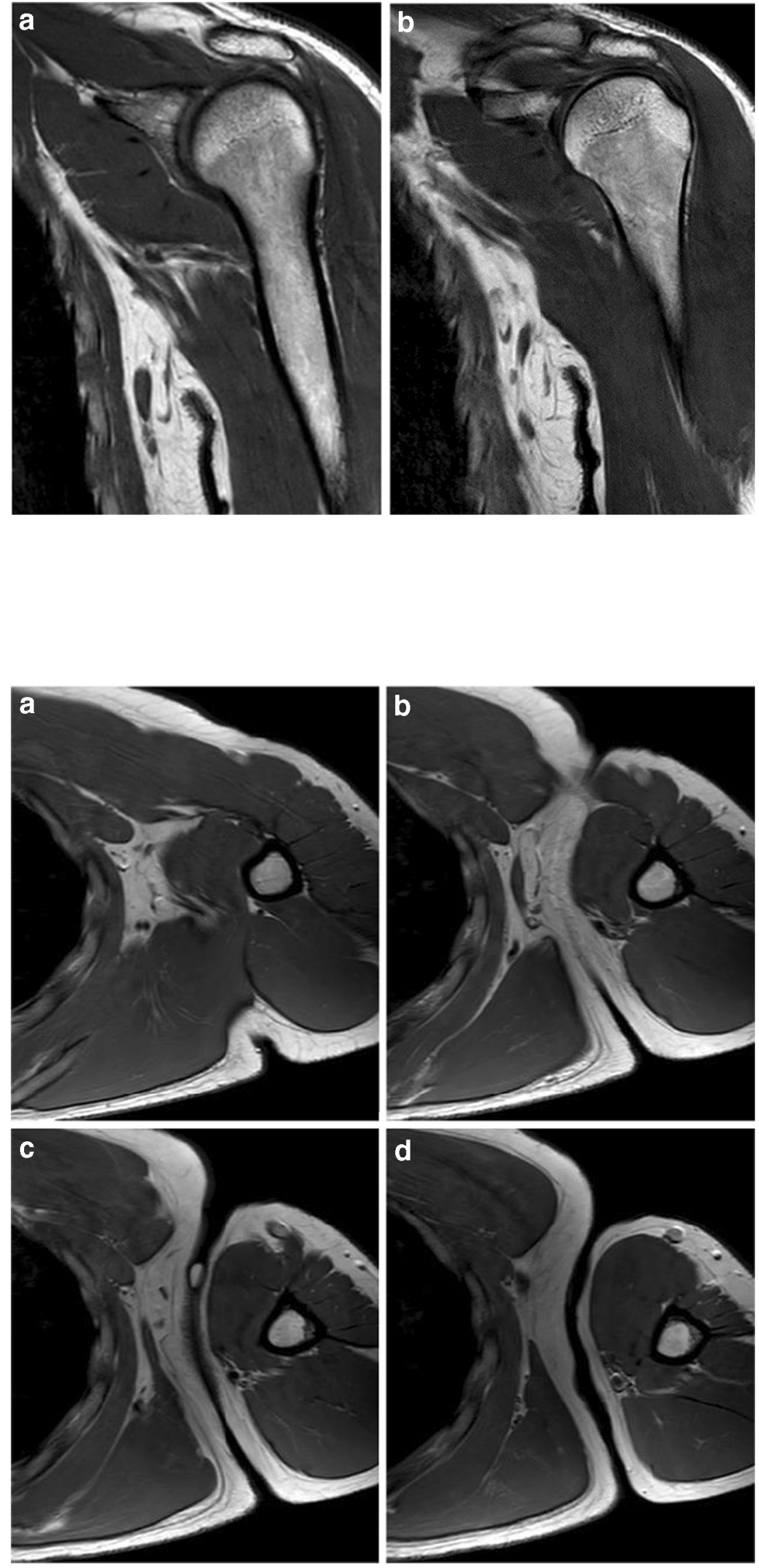